\title{
Inflammatory Mediators of Hepatic Steatosis
}

\author{
Elizabeth Hijona, ${ }^{1}$ Lander Hijona, ${ }^{2}$ Juan I. Arenas, ${ }^{1}$ and Luis Bujanda ${ }^{1}$ \\ ${ }^{1}$ Gastroenterology Department, Donostia Hospital, CIBERehd, University of the Basque Country, 20010 San Sebastián, Spain \\ ${ }^{2}$ Gastroenterology Department, Basurto Hospital, 48013 Bilbao, Spain
}

Correspondence should be addressed to Luis Bujanda, medik@telefonica.net

Received 26 November 2009; Revised 10 January 2010; Accepted 10 February 2010

Academic Editor: Giuseppe Matarese

Copyright (C) 2010 Elizabeth Hijona et al. This is an open access article distributed under the Creative Commons Attribution License, which permits unrestricted use, distribution, and reproduction in any medium, provided the original work is properly cited.

Nonalcoholic fatty liver disease (NAFLD) is rapidly becoming a world-wide public health problem. NAFLD represents a spectrum of disease ranging from "simple steatosis", which is considered relatively benign, to nonalcoholic steatohepatitis and to NAFLDassociated cirrhosis and end-stage liver disease. The etiology of NAFLD and its progression is complex and remains incompletely understood. The progression of the disease involves many factors. Apart from the two hits, the accumulation of TG and the development of fibrosis and necroinflammatory processes, exit numerous molecules associated with these two hits. Among them we can highlight the pro-inflammatory molecules and adiponectins. This review focuses on the growing evidence from both experimental and human studies suggesting a central role of cytokines in the pathogenesis of NAFLD. We review the role of cytokines as key regulators of insulin sensitivity and hepatic lipid overloading, liver injury and inflammation, and fibrosis with an emphasis on potential therapeutic implications.

\section{Introduction}

Nonalcoholic fatty liver disease (NAFLD) is a chronic inflammatory disease involving a wide range of disorders: from simple steatosis; through steatohepatitis, fibrosis and cirrhosis; to hepatocarcinoma. Historically, steatosis has been considered a benign disease. However, it is a necessary requirement for the development of NAFLD, characterized by the accumulation of lipids in the cytoplasm of hepatocytes. Its prevalence is not well known, but it is estimated to be higher than $3 \%$. It is a complex disease in which many factors play a role including obesity, insulin resistance, and oxidative stress, among others.

Nonalcoholic fatty liver disease (NAFLD) is characterized by liver damage similar to that caused by alcohol, but which occurs in individuals that do not consume toxic quantities of alcohol [1-10]. The prevalence of NAFLD is not well known, but according to various studies, ranges between $3 \%$ and $24 \%$ [11-17]. It is likely that its prevalence will increase in the future, due to an increase in the prevalence of being overweight and obesity [18-21].

\section{Etiology}

NAFLD has been associated with many etiological factors [ 1 , $2,22]$, the most common ones being obesity, type 2 diabetes mellitus, and dyslipidemia. In most series, one, two, or three factors occur in $80 \%$ and $95 \%$ of individuals. The association between diabetes or intolerance to glucose and two or more of the following clinical signs: obesity, hyperlipidemia, high blood pressure, and hypoalbuminemia is known as metabolic syndrome $\mathrm{X}[18,21,23]$. This syndrome is also associated with NAFLD.

Obesity ( $>10 \%$ of normal weight or Body Mass Index >30) (BMI) is the most common cause of NAFLD: approximately $80 \%$ of patients are obese, and the opposite is also true, $80 \%$ obese people suffer from NAFLD [24-27].

Obesity and being overweight are problems of growing importance in developed societies due to their prevalence, not only in adults but also in children $[28,29]$. They cause several metabolic and associated disorders, such as resistance to insulin, diabetes, and dyslipidemia [30]. Obesity is also known to be a risk factor for chronic diseases such as: 
diabetes, high blood pressure, heart and cerebrovascular diseases, and some types of cancer [31-33].

\section{Pathogenesis}

The exact pathogenic mechanisms involved are still not well known. However, available evidence has enabled a tenable theory of pathogenesis to be proposed involving two stages, known as "two-hit theory" [4, 34-37].

3.1. Two Hits Theory. The first hit of steatosis, giving rise to the first lesions is caused by excess free fatty acids (FFA) in the liver, which are sterified to triglycerides (TG) $[38,39]$. These initial lesions make the liver vulnerable to aggressive factors of the second hit, which is caused by the oxidative stress and proinflammatory cytokines (TNF- $\alpha$, TGF-beta, IL-6, IL-8). This leads to the occurrence of lesions in the hepatocytes, inflammation and fibrosis, and consequently the evolution of hepatic steatosis to steatohepatitits. Some poorly understood genetic factors may explain whether steatosis evolves to steatohepatitis or not $[16,34,36,37,39-41]$.

3.1.1. First Hit. A feature of obesity, type 2 diabetes, hyperlipidemia and metabolic syndrome $\mathrm{X}$ is resistance to insulin [36, 42-44]. Adipocyte insensitivity to insulin inhibits the regulation of the lipase in the adipose tissue, and large quantities of free fatty acids (FFAs) are released [41, 45-48]. Oversupply of FFAs to the liver is the main mechanism that leads to steatosis in these patients. However there are also other mechanisms. One of these is an increase of insulinemia, whether or not caused by insulin resistance, which inhibits the carnitine palmitoyltransferase enzyme, and this reduces the mytochondria beta-oxidation of FFAs [5, 49-51]. Hyperinsulinism also decreases the synthesis of apolipoprotein B-100 in the liver, which causes a decrease in the secretion of very low density lipoproteins (VLDL) [52, 53]. Finally, excess production of exogenous and endogenous glucose (in obesity and diabetes respectively), together with hyperinsulinemia, increase the synthesis of FFAs in the liver. The final result is a positive FFA balance, from oversupply and/or failure in lipid, leading to accumulation in the liver. It is not well understood why not all patients with risk factors (obesity, type 2 diabetes mellitus, hyperlipidemia) develop NAFLD. Recently, it has been demonstrated that patients with NAFLD have an increased prevalence of polymorphism in TNF- $\alpha 238$ (TNFA allele), inducing an overexpression of TNF- $\alpha$ in adipose tissue, and this, in turn, disrupts insulin receptors, causing resistance to insulin [53-55]. The transcription factor HNF3 $\alpha$ (hepatocyte nuclear factor) is an important target for research. Its presence is related to the inhibition of the accumulation of fatty acids. If overexpressed, this transcription factor triggers a reduction in the synthesis of fatty acids; that is, it has an opposite effect to steatosis [56-58].

3.1.2. Second Hit. FFAs cause an increase in the expression of cytochrome P-450 2E1 (CYP 2E1). This is a microsomal enzyme that takes part in the beta-oxidation of long and very long chain FFAs, causing the production of reactive oxygen metabolites [59]. On the other hand, some longchain FFAs are metabolized by peroxisomal beta-oxidation. This oxidation generates hydrogen peroxide, that produces hydroxyl radicals in the presence of iron, both being also reactive oxygen metabolites [60]. The excess of reactive oxygen metabolites depletes natural antioxidants such as glutathione and vitamin $\mathrm{E}$ in the liver, causing oxidative stress resulting in lipid peroxidation $[26,35,39]$. In turn, this causes damage in the hepatocyte organelles and membranes, leading to degeneration and hepatocellular necrosis [26]. The damage caused by lipid peroxidation in mitochondria, apart from changing their morphology (megamitochondria), distorts the transfer of electrons in the respiratory chain and this results in more production of reactive oxygen metabolites, closing the cycle by causing more oxidative stress $[7,16,61-$ 63].

Oxidative stress activates the Fas ligand and nuclear factor kappa $\beta$ (NF-kappa $\beta$ ). The former causes degeneration and hepatocyte death, and the latter stimulates the synthesis of proinflammatory cytokines (TNF- $\alpha$, TGF- $\beta$, IL-8) [22]. In addition, the final products of lipid peroxidation, malonaldehyde and 4-hydroxynonenal have chemotactic properties, activating proinflammatory cytokines (TNF- $\alpha$, TGF- $\beta$, IL6 , IL-8) and stimulating hepatic collagen-producing stellate cells. The end result is a mixed lesion, known as steatohepatitis, characterized by degeneration and hepatocyte necrosis, inflammatory infiltrate and fibrosis, as well as steatosis [1,22]. Malonaldehyde and 4-hydroxynonenal are also covalently bound to proteins and produce protein clusters with antigenic properties. Secondarily, antibodies may appear, which are able to cause immune-mediated hepatocellular injury (autoimmune hepatitis) [64]. One of these protein inclusions corresponds to Mallory's hyaline [64]. Ongoing oxidative stress and lipid peroxidation results in the continued production of collagen leading to fibrosis reaching the stage of hepatic cirrhosis $[1,36]$.

The passage of endotoxins from the intestine to the splenic circulation causes portal endotoxemia. Endotoxins stimulate the synthesis of proinflammatory cytokines in the liver [36]. This mechanism is essential in the development of steatohepatitis associated with intestinal bypass, since this type of surgery encourages bacterial overgrowth and endotoxemia from the dysfunctionalised loop [36]. Obese patients have intense intrahepatic expression of the enzyme nitric oxide synthase [26], which is induced by endotoxins and TNF- $\alpha$; furthermore, obese mice have been found to suffer from hepatic hypersensitivity which causes them to develop more severe degrees of steatohepatitis [4].

In this complex context, the role of several molecules are involved.

Leptin. Leptin is an adipocyte-secreted, negative feedback hormone that acts on the hypothalamus to regulate both food intake and energy expenditure [65-67]. Leptin levels are elevated in obesity [68]. It is believed that leptin has a lipostatic function: when the quantity of fat stored in the adipocytes increases, leptin is released into the bloodstream. 
This constitutes a negative feedback signal to the hypothalamus, informing the hippocampus that the body has enough food and the appetite should be reduced. When the adipose tissue mass increases a certain level beyond equilibrium, there is an increase of the synthesis and secretion of leptin, triggering several compensating effects in the hypothalamus: a decrease in appetite by the production of anorexigenic peptides (inducing loss of appetite) and the suppression of orexigenic peptides; an increase in energy expenditure by increasing of the basal metabolism and body temperature; and also a change in the equilibrium levels of hormones to reduce lipogenesis (production of fats) and to increase lipolisis (use of the body fat stored to produce energy) in the adipose tissue. The regulation of the secretion of leptin takes place on long timescales, mainly due to variations in body mass and stimulating effects of insulin. Note however that many obese people have high concentrations of leptin in serum, or resistance to leptin, suggesting that other molecules such as ghrelin, serotonin, cholecystokinin, and the neuropeptide $\mathrm{Y}$ also have an effect in the sensation of satiety and contribute to body mass regulation. Specifically, the secretion of leptin is correlated to body mass. It prevents the occurrence of NAFLD, indirectly though the central neural pathway, and directly through the activation of AMPK (AMP-activated protein kinase) [69-72]. Indeed, in patients with NAFLD it has been observed that leptin levels are directly correlated to the severity of the disease.

Leptin deficient ob/ob mice show markedly reduced levels of energy expedenditure and become obese even when pair fed compared with littermate controls. The marked steatosis observed in this group indicates that leptin prevents fatty liver, both indirectly, through central neural pathways, and directly via hepatic activation of adenosine monophosphate-activated protein kinase (AMPK) [69-71].

In patients with NAFLD, the analysis of circulating levels of leptin, has provided results more conflicting. Leptin levels found to be increased in nonalcoholic steatohepatitis, independently of BMI, with higher in patients with advanced disease [73]. In an other study, leptin levels directly correlated with the severity of steatosis but not with inflammation or fibrosis [74]. The strong evidence for leptin as a fibrogenic agent in animal models is not clearly paralleled by evidence on circulating levels in patients [71].

Adiponectin. (Also known as Acrp30, AdipoQ, apM1 o GBP28), a hormone synthesized exclusively by the adipose tissue takes part in the metabolism of glucose and fatty acids. It is secreted by adipocytes and is considered as an anti-inflammatory adipokine [68]. In general, adiponectin reduces inflammation, stimulating secretion of anti-inflammatory cytokines (e.g., IL-10), blocking NF$\mathrm{KB}$ activation, and inhibiting realease of TNF- $\alpha$, IL- 6 and chemokines [75]. Adiponectin concentrations inversely correlated with fat mass and are down-regulated in obesity and type 2 diabetes. Adiponectin exerts insulin-sensitizing effects in the liver, skeletal muscle, and adipose tissue. Like leptin, adiponectin regulates whole-body lipid partitioning and has hepatoprotective and antifibrogenic effect in condition of liver injury [68].
In experimental alcoholic and nonalcoholic models, the administration of adiponectin, ameliorated necroinflammation, and steatosis, partly via inhibition of TNF- $\alpha$ [76]. In obese mice, the administration of adiponectin improved liver injury, increasing PPAR- $\alpha$ and reducing TNF- $\alpha$ [77].

In patients with nonalcoholic steatohepatitis, adiponectin levels were reduced in comparison with control and simple steatosis patients [78]. Bugianesi et al. [79] found that adiponectin levels correlate with suppression of endogenous glucose production and predict the presence of the metabolic syndrome. However, adiponectin levels was inversely associated only with intrahepatic fat but not with inflammation and fibrosis. In patients with diabetes, levels of adiponectin are inversely correlated to hepatic fat content and to endogenous glucose production. This hit suggests, that adiponectin may represent a link between hepatic fat and insulin resistance (IR) [80]. Also, gentic factors produce alterations in the adiponectin levels. Polymorphisms of the adiponectin gene have been associated with higher risk of type 2 diabetes and cardiovascular disease [81].

Interleukin-6 (IL-6). It has a pleiotropic action, and in animals models it has been associated with protection of steatosis [71]. It is associated with hyperinsulinaemia and IR [82].

IL-6 is overexpressed in the adipose tissue of obese patiens [71]. Increased hepatic IL-6 production may play an important role in NASH development, as well as in systemic insulin resistance and diabetes [83]. Chronically elevated IL6 levels lead to inappropriate hyperinsulinaemia, reduced body weight, impaired insulin-stimulated glucose uptake by the skeletal muscles and marked inflammation in the liver. Thus, the pleiotrophic effects of chronically elevated IL-6 levels preclude any obvious usefulness in treating obesity or its associated metabolic complications in man, despite the fact that weight reduction may be expected [82].

Resistin. Resistin is a recently discovered adipokine, secreted by adipose tissue and macrophages [68].

Several rodent models shown that resistin may be a link between IR and obesity [70]. In resistin-deficient mice placed on high-fat diet, fatty infiltration and secretion of low density lipoprotein are decreased. This suggests, a role of resistin in the induction of hepatic steatosis [84].

In humans, the biology of resistin is not clearly defined. Most studies demonstrates that resistin is expressed by bone marrow [72].

\section{Genetic Factors}

Not all patients with similar risk factors (obesity, diabetes, hyperlipidemia, etc.) develop steatosis. Moreover, as with alcoholic steatosis, not all the patients with simple steatosis go on to develop the lesions characteristic of steatohepatitis nor do all patients with steatohepatitis reach the stage of cirrhosis, and those that do take widely varying times to develop the condition. It has been suggested that this range of outcomes may depend on some genetically determined 
factors, such as genetic polymorphism in the CYP2E1, TNF$\alpha$, or IL-10 promoter regions [1]. In NAFLD, these genetic factors are unknown but it has been suggested that the development of steatosis may depend on the occurrence of alterations in the genes involved in insulin resistance, or in those codifying proteins that are involved in the hepatic metabolism of lipids [85].

\section{Future Therapeutic Targets}

The basic pillars to the treatment of NAFLD include weight loss and change in lifestyle. Currently, are using different types of drugs for the treatment of non-alcoholic steatosis. Among them we highlight the antidiabetic agents such as pioglitazone, rosiglitazone, troglitazone, and metformin. Rosiglitazone and troglitazone have been retired from the market because it produced severe liver damage [86]. Metformin is the molecule being tested today, as it can reduce the steatosis [87]. On the other hand, they have used drugs with antioxidant powers as betaine, $\mathrm{N}$-acetylcysteine, Vitamin $\mathrm{E}$, and other drugs, that apart from its antioxidant properties, have cytoprotective properties, as ursodeoxycholic acid. Finally, they have also been used as anticitoquines drugs antiTNF/Infliximab [88].

All these studies are very preliminary. It is necessary to test new drugs that have been able to stop steatosis. Among the new drugs being tested, we emphasize the Allopurinol [89], omega-3 fatty acids [90], bezafibrate [91], the combination of ezetimibe/simvastatin [92], SRT1720 (SIRT1 activator) [93], Viusid (nutritional supplement) [94], Pan-caspase [95], bicyclol [96] and Losartan [97] among others. It has been observed that these drugs may be promising, as they decrease injuries NAFLD. But remember that these studies have been realized in animals and are necessary human trials.

The above-mentioned molecules, represent a convincing target for the development of novel therapies in liver diseases, and adiponectins appear as the forerunner candidate.

Adiponectin concentrations are reduced in people suffering from obesity, type 2 diabetes mellitus and coronary arterial disease $[71,76,98]$. The proinflammatory cytokines TNF- $\alpha$ and IL- 6 play important roles in obesity and the evolution of the disease [99-102]. Another target of interest is the constitutive androstane receptor (CAR). It improves the sensitivity to glucose and steatosis by inhibiting hepatic lipogenesis and inducin $\beta$-oxidation [103]. Also, the peroxisome proliferator-activated receptor (PPAR $\alpha)$ is responsible for the increase in the oxidation of fatty acids and decreases blood levels of triglycerides. In patients with steatosis, it has been observed that its levels decrease considerably [104], while those of the prolipogenic transcription factor Sterol Regulatory Element Binding Proteins (SERBP-1c) significantly increase [105]. For these reasons, PPAR $\alpha$ is also considered to be an interesting target to study in relation to lipid metabolism and obesity [104-106]

In the not too distant future, we must be able to diagnose steatosis, without using invasive methods. Today, for the diagnosis, liver biopsy is used, but it would be very interesting to be able to perform diagnosis using noninvasive techniques. For example, determining the amount of liver fat by magnetic resonance techniques. It would be very useful to perform a predictive test, but for this, we need much more research about the interaction of different factors, molecules, and genes [107]. The identification of the molecular mechanism leading to fat accumulation and oxidative imbalance in steatotic livers, as well as genome and proteome studies from patients to various stages of the disease, is expected to improve the diagnostic and therapeutic approaches. In this way, attractive pharmacological designs include new molecules which can be able to decrease lipid from livers and to improve insulin sensitivity.

The apparence of novel approaches is eagerly awaited.

\section{Acknowledgment}

CIBEREHD is funded by the Instituto de Salud Carlos III, from the Spanish Ministry of Health.

\section{References}

[1] G. Castellano, "Esteatohepatitis no alcohólica," Gastroenterol Hepatol, vol. 22, pp. 13-19, 1999.

[2] A. J. McCullough, "Update on nonalcoholic fatty liver disease," Journal of Clinical Gastroenterology, vol. 34, no. 3, pp. 255-262, 2002.

[3] L. A. Adams, J. F. Lymp, J. St. Sauver, et al., "The natural history of nonalcoholic fatty liver disease: a population-based cohort study," Gastroenterology, vol. 129, no. 1, pp. 113-121, 2005.

[4] M. C. García, "Non-alcoholic steatohepatitis," Journal of Gastroenterology and Hepatology, vol. 24, pp. 395-402, 2001.

[5] J. K. Reddy and M. S. Rao, "Lipid metabolism and liver inflammation. II. Fatty liver disease and fatty acid oxidation," American Journal of Physiology, vol. 290, no. 5, pp. G852G858, 2006.

[6] J. B. Schwimmer, C. Behling, R. Newbury, et al., "Histopathology of pediatric nonalcoholic fatty liver disease," Hepatology, vol. 42, no. 3, pp. 641-649, 2005.

[7] J. A. Solís Herruzo, R. García, M. Pérez Carreras, and M. T. Muñoz Yagüe, "Non-alcoholic fatty liver disease. From insulin resistance to mitochondrial dysfunction," Revista Espanola de Enfermedades Digestivas, vol. 98, no. 11, pp. 844874, 2006.

[8] Y. Wei, R. S. Rector, J. P. Thyfault, and J. A. Ibdah, "Nonalcoholic fatty liver disease and mitochondrial dysfunction," World Journal of Gastroenterology, vol. 14, no. 2, pp. 193-199, 2008.

[9] J. George and C. Liddle, "Nonalcoholic fatty liver disease: pathogenesis and potential for nuclear receptors as therapeutic targets," Molecular Pharmaceutics, vol. 5, no. 1, pp. 49-59, 2008.

[10] D. Preiss and N. Sattar, "Non-alcoholic fatty liver disease: an overview of prevalence, diagnosis, pathogenesis and treatment considerations," Clinical Science, vol. 115, no. 5-6, pp. 141-150, 2008.

[11] Y. Falck-Ytter, Z. M. Younossi, G. Marchesini, and A. J. McCullough, "Clinical features and natural history of nonalcoholic steatosis syndromes," Seminars in Liver Disease, vol. 21, no. 1, pp. 17-26, 2001. 
[12] M. Pérez-Carreras, G. Castellano, and M. A. Gutiérrez, "Esteatohepatitis no alcohólica: una entidad no tan infrecuente," Revista Española de Enfermedades Digestivas, vol. 90, pp. 240-241, 1998.

[13] V. Piñol, X. Bessa, M. Bruguera, and J. Rodés, "Esteatosis y esteatohepatitis no alcohólica. Análisis comparativo," Gastroenterologia y Hepatologia, vol. 23, no. 2, pp. 57-61, 2000.

[14] G. Castellano, "The natural history of hepatitis C virus infection," Nephrology Dialysis Transplantation, vol. 15, pp. $19-23,2000$.

[15] M. Duvnjak, I. Lerotić, N. Baršić, V. Tomašić, L. V. Jukić, and V. Velagić, "Pathogenesis and management issues for nonalcoholic fatty liver disease," World Journal of Gastroenterology, vol. 13, no. 34, pp. 4539-4550, 2007.

[16] S. A. Harrison, S. Kadakia, K. A. Lang, and S. Schenker, "Nonalcoholic steatohepatitis: what we know in the new millennium," American Journal of Gastroenterology, vol. 97, no. 11, pp. 2714-2724, 2002.

[17] M. Lazo and J. M. Clark, "The epidemiology of nonalcoholic fatty liver disease: a global perspective," Seminars in Liver Disease, vol. 28, no. 4, pp. 339-350, 2008.

[18] G. Targher, L. Bertolini, R. Padovani, et al., "Increased prevalence of cardiovascular disease in type 2 diabetic patients with non-alcoholic fatty liver disease," Diabetic Medicine, vol. 23, no. 4, pp. 403-409, 2006.

[19] J. Fehér, E. Németh, and G. Lengyel, "Non-alcoholic steatohepatitis (NASH)," Archives of Medical Science, vol. 1, no. 1, pp. 37-47, 2005.

[20] G. Bedogni, L. Miglioli, F. Masutti, C. Tiribelli, G. Marchesini, and S. Bellentani, "Prevalence of and risk factors for nonalcoholic fatty liver disease: the dionysos nutrition and liver study," Hepatology, vol. 42, no. 1, pp. 44-52, 2005.

[21] E. Dembowski and M. H. Davidson, "Role of statin therapy in the management of patients with the metabolic syndrome," Archives of Medical Science, vol. 3, no. 4, pp. S102-S108, 2007.

[22] P. Angulo, "Medical progress: nonalcoholic fatty liver disease," The New England Journal of Medicine, vol. 346, no. 16, pp. 1221-1231, 2002.

[23] G. M. Reaven, "Syndrome X: 6 years later," Journal of Internal Medicine, vol. 236, no. 736, pp. 13-22, 1994.

[24] D. Moreno and G. Castellano, "El hígado en la obesidad," Journal of Gastroenterology and Hepatology, vol. 16, pp. 550$558,1993$.

[25] W. I. Youssef and A. J. McCullough, "Steatohepatitis in obese individuals," Bailliere's Best Practice and Research in Clinical Gastroenterology, vol. 16, no. 5, pp. 733-747, 2002.

[26] C. García-Monzón, E. Martín-Pérez, O. L. Iacono, et al., "Characterization of pathogenic and prognostic factors of nonalcoholic steatohepatitis associated obesity," Journal of Hepatology, vol. 33, no. 5, pp. 716-724, 2000.

[27] L. A. Adams, M. W. Knuiman, M. L. Divitini, and J. K. Olynyk, "Body mass index is a stronger predictor of alanine aminotransaminase levels than alcohol consumption," Journal of Gastroenterology and Hepatology, vol. 23, no. 7, pp. 1089-1093, 2008.

[28] H. R. Berthoud, "Homeostatic and non-homeostatic pathways involved in the control of food intake and energy balance," Obesity, vol. 14, supplement 5, pp. 197S-200S, 2006.

[29] C. Pérez-Rodrigo, J. A. Bartrina, L. S. Majem, B. Moreno, and A. D. Rubio, "Epidemiology of obesity in Spain. Dietary guidelines and strategies for prevention," International Journal for Vitamin and Nutrition Research, vol. 76, no. 4, pp. 163-171, 2006.
[30] S. Allender and M. Rayner, "The burden of overweight and obesity-related ill health in the UK," Obesity Reviews, vol. 8, no. 5, pp. 467-473, 2007.

[31] T. Ábel and J. Fehér, "Non-alcoholic fatty liver disease and cardiovascular risk," Hungarian Medical Journal, vol. 2, pp. 509-518, 2008.

[32] S. Sookoian and C. J. Pirola, "Non-alcoholic fatty liver disease is strongly associated with carotid atherosclerosis: a systematic review," Journal of Hepatology, vol. 49, no. 4, pp. 600-607, 2008.

[33] A. Kumar and C. P. Cannon, "The current role of statins in acute coronary syndrome," Archives of Medical Science, vol. 3, no. 4, pp. S115-S125, 2007.

[34] C. P. Day and O. F. W. James, "Steatohepatitis: a tale of two "Hits"?" Gastroenterology, vol. 114, no. 4, pp. 842-845, 1998.

[35] B.A. Neuschwander-Tetri and S. H. Caldwell, "Nonalcoholic steatohepatitis: summary of an AASLD Single Topic Conference," Hepatology, vol. 37, no. 5, pp. 1202-1219, 2003.

[36] S. Chitturi and G. C. Farrell, "Etiopathogenesis of nonalcoholic steatohepatitis," Seminars in Liver Disease, vol. 21, no. 1, pp. 27-41, 2001.

[37] O. James and C. Day, "Non-alcoholic steatohepatitis: another disease of affluence," The Lancet, vol. 353, no. 9165, pp. 16341636, 1999.

[38] M. Charlton, R. Sreekumar, D. Rasmussen, K. Lindor, and K. S. Nair, "Apolipoprotein synthesis in nonalcoholic steatohepatitis," Hepatology, vol. 35, no. 4, pp. 898-904, 2002.

[39] A. J. Sanyal, C. Campbell-Sargent, F. Mirshahi, et al., "Nonalcoholic steatohepatitis: association of insulin resistance and mitochondrial abnormalities," Gastroenterology, vol. 120, no. 5, pp. 1183-1192, 2001.

[40] S. Q. Yang, H. Z. Lin, M. D. Lane, M. Clemens, and A. M. Diehl, "Obesity increases sensitivity to endotoxin liver injury: implications for the pathogenesis of steatohepatitis," Proceedings of the National Academy of Sciences of the United States of America, vol. 94, no. 6, pp. 2557-2562, 1997.

[41] C. M. Oneta and J.-F. Dufour, "Non-alcoholic fatty liver disease: treatment options based on pathogenic considerations," Swiss Medical Weekly, vol. 132, no. 35-36, pp. 493-505, 2002.

[42] R. U. Macías-Rodríguez and A. Torre, "Pathophysiology of non-alcoholic steatohepatitis. An insulin resistance overview," Revista de Investigacion Clinica, vol. 61, no. 2, pp. 161-172, 2009.

[43] G. Pagano, G. Pacini, G. Musso, et al., "Nonalcoholic steatohepatitis, insulin resistance, and metabolic syndrome: further evidence for an etiologic association," Hepatology, vol. 35, no. 2, pp. 367-372, 2002.

[44] M. Pérez-Carreras, C. Vargas, G. Castellano, et al., "Metabolismo de la glucosa/insulina en la esteatohepatitis no alcohólica," Journal of Gastroenterology and Hepatology, vol. 24, supplement, pp. 94-100, 2001.

[45] E. Fabbrini, B. S. Mohammed, F. Magkos, K. M. Korenblat, B. W. Patterson, and S. Klein, "Alterations in adipose tissue and hepatic lipid kinetics in obese men and women with nonalcoholic fatty liver disease," Gastroenterology, vol. 134, no. 2, pp. 424-431, 2008.

[46] B. B. Kahn and J. S. Flier, "Obesity and insulin resistance," Journal of Clinical Investigation, vol. 106, no. 4, pp. 473-481, 2000.

[47] K. Eto, T. Yamashita, J. Matsui, Y. Terauchi, M. Noda, and T. Kadowaki, "Genetic manipulations of fatty acid metabolism in $\beta$-cells are associated with dysregulated insulin secretion," Diabetes, vol. 51, supplement 3, pp. S414-S420, 2002. 
[48] M. Haque and A. J. Sanyal, "The metabolic abnormalities associated with non-alcoholic fatty liver disease," Bailliere's Best Practice and Research in Clinical Gastroenterology, vol. 16, no. 5, pp. 709-731, 2002.

[49] G. P. Mannaerts, P. P. Van Veldhoven, and M. Casteels, "Peroxisomal Lipid Degradation via $\beta$ - and $\alpha$-oxidation in Mammals," Cell Biochemistry and Biophysics, vol. 32, pp. 7387,2000

[50] J. K. Reddy and T. Hashimoto, "Peroxisomal $\beta$-oxidation and peroxisome proliferator-activated receptor $\alpha$ : an adaptive metabolic system," Annual Review of Nutrition, vol. 21, pp. 193-230, 2001.

[51] D. G. Fong, V. Nehra, K. D. Lindor, and A. L. Buchman, "Metabolic and nutritional considerations in nonalcoholic fatty liver," Hepatology, vol. 32, no. 1, pp. 3-10, 2000.

[52] M. Charlton, R. Sreekumar, D. Rasmussen, K. Lindor, and K. S. Nair, "Apolipoprotein synthesis in nonalcoholic steatohepatitis," Hepatology, vol. 35, no. 4, pp. 898-904, 2002.

[53] L. Valenti, A. L. Fracanzani, P. Dongiovanni, et al., "Tumor necrosis factor $\alpha$ promoter polymorphisms and insulin resistance in nonalcoholic fatty liver disease," Gastroenterology, vol. 122, no. 2, pp. 274-280, 2002.

[54] J.-M. Fernández-Real, M. Broch, J. Vendrell, et al., “Tumour necrosis factor- $\alpha$ (TNF- $\alpha$ ) polymorphisms -857C/A and $863 \mathrm{C} / \mathrm{A}$ are associated with TNF- $\alpha$ secretion from human adipose tissue. Diabetologia 44: 654-655," Diabetologia, vol. 45, no. 1, pp. 149-150, 2002.

[55] J. Crespo, A. Cayoen, P. Fernendez-Gil, et al., "Gene expression of tumor necrosis factor $\alpha$ and TNF-receptors, p55 and p75, in nonalcoholic steatohepatitis patients," Hepatology, vol. 34, no. 6, pp. 1158-1163, 2001.

[56] N. Li and C. D. Klaassen, "Role of liver-enriched transcription factors in the down-regulation of organic anion transporting polypeptide 4 (Oatp4; Oatplb2; Slc21a10) by lipopolysaccharide," Molecular Pharmacology, vol. 66, no. 3, pp. 694-701, 2004.

[57] D. E. Hughes, D. B. Stolz, S. Yu, et al., "Elevated hepatocyte levels of the Forkhead box A2 (HNF-3 $\beta$ ) transcription factor cause postnatal steatosis and mitochondrial damage," Hepatology, vol. 37, no. 6, pp. 1414-1424, 2003.

[58] N. Morral, H. J. Edenberg, S. R. Witting, J. Altomonte, T. $\mathrm{Chu}$, and M. Brown, "Effects of glucose metabolism on the regulation of genes of fatty acid synthesis and triglyceride secretion in the liver," Journal of Lipid Research, vol. 48, no. 7, pp. 1499-1510, 2007.

[59] M. D. Weltman, G. C. Farrell, P. Hall, M. IngelmanSundberg, and C. Liddle, "Hepatic cytochrome P450 2E1 is increased in patients with nonalcoholic steatohepatitis," Hepatology, vol. 27, no. 1, pp. 128-133, 1998.

[60] M. Rao and J. K. Reddy, "Peroxisomal beta-oxidation and steatohepatitis," Seminars in Liver Disease, vol. 21, pp. 43-55, 2001.

[61] M. Pérez-Carreras, P. del Hoyo, M. A. Martin, et al., "Activity of the mitochondrial respiratory chain enzymes is increased in the liver of patients with nonalcoholic steatohepatitis," Hepatology, vol. 30, supplement, p. 379A, 1999.

[62] J. D. Browning and J. D. Horton, "Molecular mediators of hepatic steatosis and liver injury," Journal of Clinical Investigation, vol. 114, no. 2, pp. 147-152, 2004.

[63] D. Pessayre, A. Mansouri, and B. Fromenty, "Nonalcoholic steatosis and steatohepatitis V. mitochondrial dysfunction in steatohepatitis," American Journal of Physiology, vol. 282, no. 2 45-2, pp. G193-G199, 2002.
[64] D. Pessayre, A. Berson, B. Fromenty, and A. Mansouri, "Mitochondria in steatohepatitis," Seminars in Liver Disease, vol. 21, no. 1, pp. 57-69, 2001.

[65] Y. Zhang, R. Proenca, M. Maffei, M. Barone, L. Leopold, and J. M. Friedman, "Positional cloning of the mouse obese gene and its human homologue," Nature, vol. 372, no. 6505, pp. 425-432, 1994.

[66] J. L. Halaas, C. Boozer, J. Blair-West, N. Fidahusein, D. A. Denton, and J. M. Friedman, "Physiological response to longterm peripheral and central leptin infusion in lean and obese mice," Proceedings of the National Academy of Sciences of the United States of America, vol. 94, no. 16, pp. 8878-8883, 1997.

[67] A. Singh, M. Wirtz, N. Parker, et al., "Leptin-mediated changes in hepatic mitochondrial metabolism, structure, and protein levels," Proceedings of the National Academy of Sciences of the United States of America, vol. 106, no. 31, pp. 13100-13105, 2009.

[68] E. A. Tsochatzis, G. V. Papatheodoridis, and A. J. Archimandritis, "Adipokines in nonalcoholic steatohepatitis: from pathogenesis to implications in diagnosis and therapy," Mediators of inflammation, vol. 2009, Article ID 831670, 8 pages, 2009.

[69] F. Andreelli, M. Foretz, C. Knauf, et al., "Liver adenosine monophosphate-activated kinase- $\alpha 2$ catalytic subunit is a key target for the control of hepatic glucose production by adiponectin and leptin but not insulin," Endocrinology, vol. 147, no. 5, pp. 2432-2441, 2006.

[70] K. Rabe, M. Lehrke, K. G. Parhofer, and U. C. Broedl, "Adipokines and insulin resistance," Molecular Medicine, vol. 14, no. 11-12, pp. 741-751, 2008.

[71] F. Marra and C. Bertolani, "Adipokines in liver diseases," Hepatology, vol. 50, no. 3, pp. 957-969, 2009.

[72] M. G. Myers, M. A. Cowley, and H. Munzberg, "Mechanisms of leptin action and leptin resistance," Annual Review of Physiology, vol. 70, pp. 537-556, 2008.

[73] A. Uygun, A. Kadayifci, Z. Yesilova, et al., "Serum leptin levels in patients with nonalcoholic steatohepatitis," American Journal of Gastroenterology, vol. 95, no. 12, pp. 3584-3589, 2000.

[74] S. Chitturi, G. Farrell, L. Frost, et al., "Serum leptin in NASH correlates with hepatic steatosis but not fibrosis: a manifestation of lipotoxicity?" Hepatology, vol. 36, no. 2, pp. 403-409, 2002.

[75] H. Tilg and A. R. Moschen, "Adipocytokines: mediators linking adipose tissue, inflammation and immunity," Nature Reviews Immunology, vol. 6, no. 10, pp. 772-783, 2006.

[76] A. Xu, Y. Wang, H. Keshaw, L. Y. Xu, K. S. L. Lam, and G. J. S. Cooper, "The fat-derived hormone adiponectin alleviates alcoholic and nonalcoholic fatty liver diseases in mice," Journal of Clinical Investigation, vol. 112, no. 1, pp. 91-100, 2003.

[77] T. Masaki, S. Chiba, H. Tatsukawa, et al., "Adiponectin protects LPS-induced liver injury through modulation of TNF- $\alpha$ in KK-Ay obese mice," Hepatology, vol. 40, no. 1, pp. 177-184, 2004.

[78] J. M. Hui, A. Hodge, G. C. Farrell, J. G. Kench, A. Kriketos, and J. George, "Beyond insulin resistance in NASH: TNF- $\alpha$ or adiponectin?" Hepatology, vol. 40, no. 1, pp. 46-54, 2004.

[79] E. Bugianesi, U. Pagotto, R. Manini, et al., "Plasma adiponectin in nonalcoholic fatty liver is related to hepatic insulin resistance and hepatic fat content, not to liver disease severity," Journal of Clinical Endocrinology and Metabolism, vol. 90, no. 6, pp. 3498-3504, 2005. 
[80] M. Bajaj, S. Suraamornkul, P. Piper, et al., "Decreased plasma adiponectin concentrations are closely related to hepatic fat content and hepatic insulin resistance in pioglitazone-treated type 2 diabetic patients," Journal of Clinical Endocrinology and Metabolism, vol. 89, no. 1, pp. 200-206, 2004.

[81] L. Qi, A. Doria, J. E. Manson, et al., "Adiponectin genetic variability, plasma adiponectin, and cardiovascular risk in patients with type 2 diabetes," Diabetes, vol. 55, no. 5, pp. 1512-1516, 2006.

[82] S. Franckhauser, I. Elias, V. Rotter Sopasakis, et al., "Overexpression of Il6 leads to hyperinsulinaemia, liver inflammation and reduced body weight in mice," Diabetologia, vol. 51, no. 7, pp. 1306-1316, 2008.

[83] A. Wieckowska, B. G. Papouchado, Z. Li, R. Lopez, N. N. Zein, and A. E. Feldstein, "Increased hepatic and circulating interleukin-6 levels in human nonalcoholic steatohepatitis," American Journal of Gastroenterology, vol. 103, no. 6, pp. 1372-1379, 2008.

[84] N. S. Singhal, R. T. Patel, Y. Qi, Y.-S. Lee, and R. S. Ahima, "Loss of resistin ameliorates hyperlipidemia and hepatic steatosis in leptin-deficient mice," American Journal of Physiology, vol. 295, no. 2, pp. E331-E338, 2008.

[85] C. P. Day, "Non-alcoholic steatohepatitis (NASH): where are we now and where are we going?" Gut, vol. 50, no. 5, pp. 585$588,2002$.

[86] A. J. McCullough, "Update on nonalcoholic fatty liver disease," Journal of Clinical Gastroenterology, vol. 34, no. 3, pp. 255-262, 2002.

[87] J. W. Haukeland, Z. Konopski, H. B. Eggesbø, et al., "Metformin in patients with non-alcoholic fatty liver disease: a randomized, controlled trial," Scandinavian Journal of Gastroenterology, vol. 44, no. 7, pp. 853-860, 2009.

[88] C. García-Monzón and F. Pons, "Enfermedad hepática grasa no alcohólica," in Enfermedades hepáticas. Consejos prácticos, R. Planas and J. Salmerón, Eds., pp. 55-61, Asociación Española Para el Estudio del Hígado, Barcelona, Spain, 2007.

[89] I. Suzuki, T. Yamauchi, M. Onuma, and S. Nozaki, "Allopurinol, an inhibitor of uric acid synthesis - can it be used for the treatment of metabolic syndrome and related disorders?" Drugs of Today, vol. 45, no. 5, pp. 363-378, 2009.

[90] G. S. Masterton, J. N. Plevris, and P. C. Hayes, "Omega3 fatty acids-a promising novel therapy for non-alcoholic fatty liver disease," to appear in Alimentary Pharmacology \& Therapeutics.

[91] M. Nakamuta, T. Fujino, R. Yada, et al., "Therapeutic effect of bezafibrate against biliary damage: a study of phospholipid secretion via the PPAR $\alpha$-MDR3 pathway," International Journal of Clinical Pharmacology and Therapeutics, vol. 48, no. 1, pp. 22-28, 2010.

[92] T. Ábel, J. Fehér, E. Dinya, M. G. Eldin, and A. Kovács, "Safety and efficacy of combined ezetimibe/simvastatin treatment and simvastatin monotherapy in patients with non-alcoholic fatty liver disease," Medical Science Monitor, vol. 15, no. 12, pp. MS6-MS11, 2009.

[93] Y. Yamazaki, I. Usui, Y. Kanatani, et al., "Treatment with SRT1720, a SIRT1 activator, ameliorates fatty liver with reduced expression of lipogenic enzymes in MSG mice," American Journal of Physiology, vol. 297, no. 5, pp. E1179E1186, 2009.

[94] E. Vilar Gomez, A. Rodriguez De Miranda, B. Gra Oramas, et al., "Clinical trial: a nutritional supplement Viusid, in combination with diet and exercise, in patients with nonalcoholic fatty liver disease," Alimentary Pharmacology and Therapeutics, vol. 30, no. 10, pp. 999-1009, 2009.
[95] R. P. Witek, W. C. Stone, F. G. Karaca, et al., "Pan-caspase inhibitor VX-166 reduces fibrosis in an animal model of nonalcoholic steatohepatitis," Hepatology, vol. 50, no. 5, pp. 1421-1430, 2009.

[96] H.-Y. Yu, B.-L. Wang, J. Zhao, X.-M. Yao, Y. Gu, and Y. Li, "Protective effect of bicyclol on tetracycline-induced fatty liver in mice," Toxicology, vol. 261, no. 3, pp. 112-118, 2009.

[97] M. S. Rosselli, A. L. Burgueño, J. Carabelli, M. Schuman, C. J. Pirola, and S. Sookoian, "Losartan reduces liver expression of plasminogen activator inhibitor-1 (PAI-1) in a high fat-induced rat nonalcoholic fatty liver disease model," Atherosclerosis, vol. 206, no. 1, pp. 119-126, 2009.

[98] M. You, R. V. Considine, T. C. Leone, D. P. Kelly, and D. W. Crabb, "Role of adiponectin in the protective action of dietary saturated fat against alcoholic fatty liver in mice," Hepatology, vol. 42, no. 3, pp. 568-577, 2005.

[99] B. Gustafson, A. Hammarstedt, C. X. Andersson, and U. Smith, "Inflamed adipose tissue: a culprit underlying the metabolic syndrome and atherosclerosis," Arteriosclerosis, Thrombosis, and Vascular Biology, vol. 27, no. 11, pp. 22762283, 2007.

[100] S. Schenk, M. Saberi, and J. M. Olefsky, "Insulin sensitivity: modulation by nutrients and inflammation," Journal of Clinical Investigation, vol. 118, no. 9, pp. 2992-3002, 2008.

[101] S. E. Shoelson, L. Herrero, and A. Naaz, "Obesity, inflammation, and insulin resistance," Gastroenterology, vol. 132, no. 6, pp. 2169-2180, 2007.

[102] F. Tacke, T. Luedde, and C. Trautwein, "Inflammatory pathways in liver homeostasis and liver injury," Clinical Reviews in Allergy and Immunology, vol. 36, no. 1, pp. 4-12, 2009.

[103] B. Dong, P. K. Saha, W. Huang, et al., "Activation of nuclear receptor CAR ameliorates diabetes and fatty liver disease," Proceedings of the National Academy of Sciences of the United States of America, vol. 106, no. 44, pp. 18831-18836, 2009.

[104] L. Zheng, G.-C. Lv, J. Sheng, and Y.-D. Yang, "Effect of miRNA-10b in regulating cellular steatosis level by targeting PPAR- $\alpha$ expression, a novel mechanism for the pathogenesis of NAFLD," Journal of Gastroenterology and Hepatology, vol. 25, no. 1, pp. 156-163, 2010.

[105] R. Sato, "SREBPs: protein interaction and SREBPs," FEBS Journal, vol. 276, no. 3, pp. 622-627, 2009.

[106] M. Yoon, "The role of PPAR $\alpha$ in lipid metabolism and obesity: focusing on the effects of estrogen on PPAR $\alpha$ actions," Pharmacological Research, vol. 60, no. 3, pp. 151159, 2009.

[107] L. N. Bell, J. I. Theodorakis, R. Vuppalanchi, et al., "Serum proteomics and biomarker discovery across the spectrum of non-alcoholic fatty liver disease," Hepatology, vol. 51, pp. 111-120, 2010. 


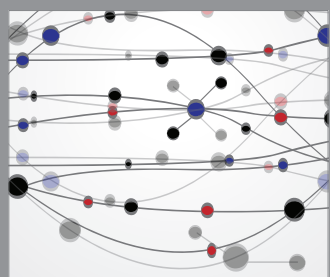

The Scientific World Journal
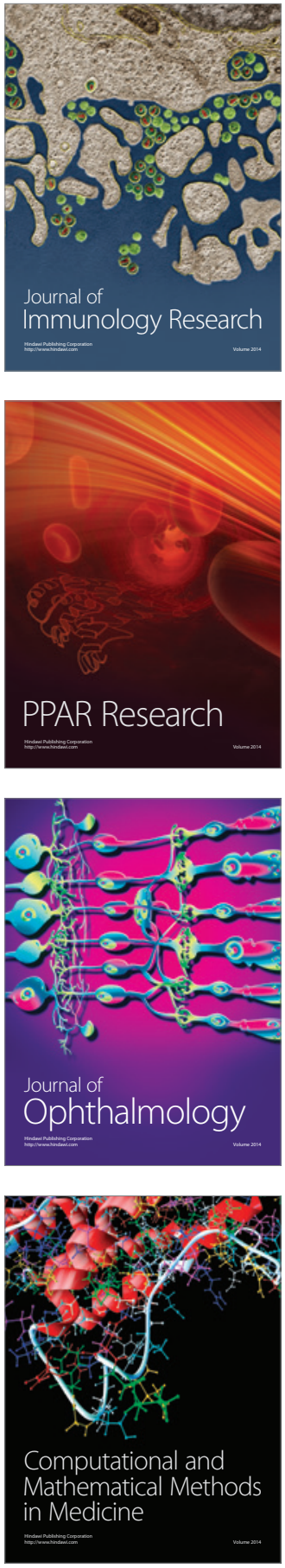

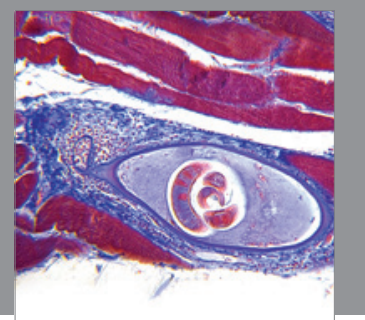

Gastroenterology

Research and Practice
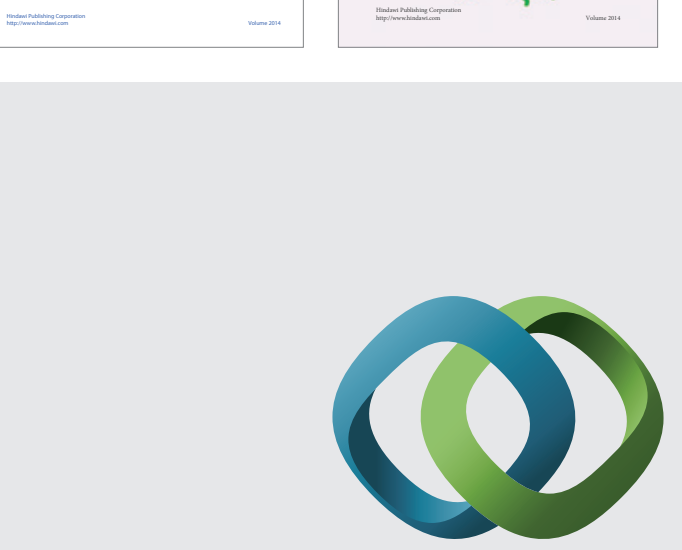

\section{Hindawi}

Submit your manuscripts at

http://www.hindawi.com
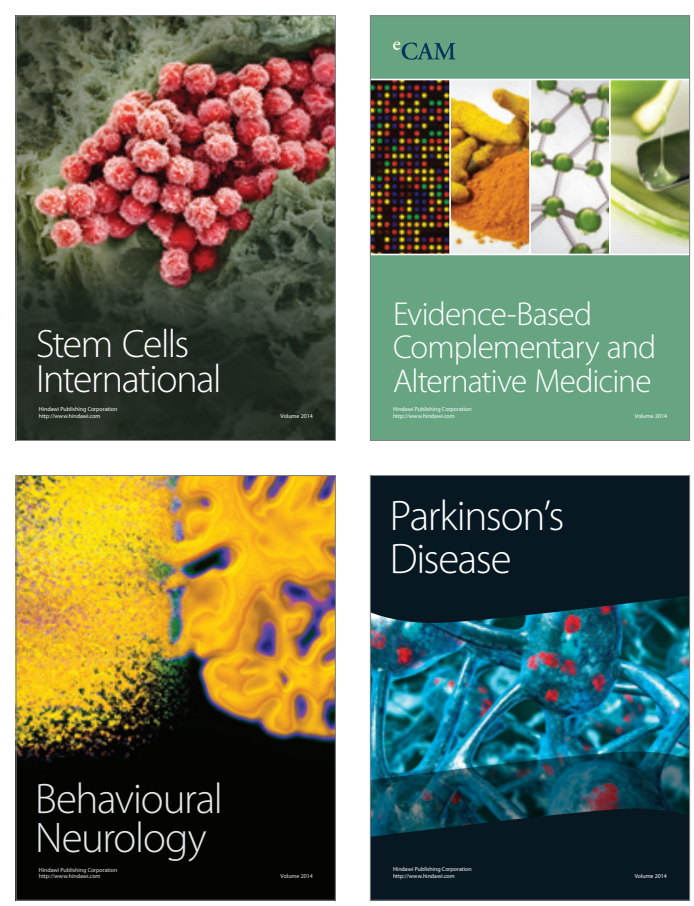

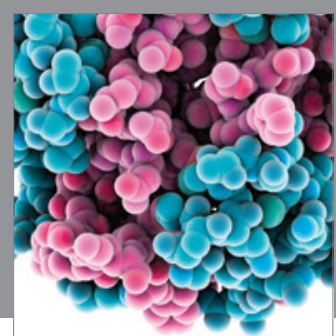

Journal of
Diabetes Research

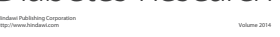

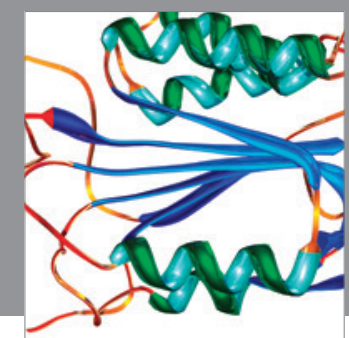

Disease Markers
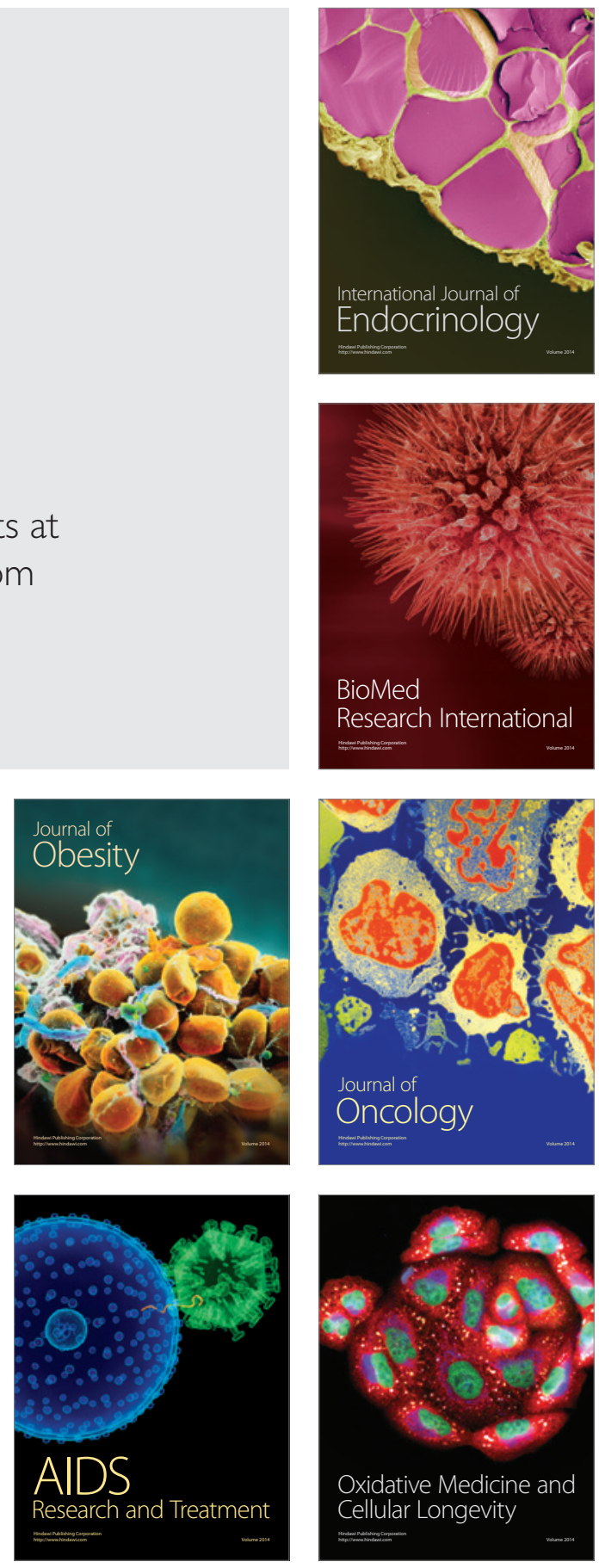